\title{
HORIZONTES CRÍTICOS ENTRE DIALÉTICA MARXISTA E INTERDISCIPLINARIDADE: UMA PERSPECTIVA À LUZ DA QUESTÃO AMBIENTAL ${ }^{1}$
}

\author{
HORIZONTES CRÍTICOS ENTRE DIALÉCTICA MARXISTA Y \\ INTERDISCIPLINARIEDAD: \\ UNA PERSPECTIVA A LUZ DA CUESTIÓN AMBIENTAL
}

\section{DIALECTIC HORIZONS BETWEEN CRITICAL AND MARXIST INTERDISCIPLINARITY: A PERSPECTIVE IN THE LIGHT OF ENVIRONMENTAL ISSUE}

\section{César Augusto Soares da $\operatorname{COSTA}^{2}$}

RESUMO: O ensaio aborda as relações entre a interdisciplinaridade e dialética marxista à luz da questão ambiental, sendo que serão analisados os vínculos que unem interdisciplinaridade enquanto prática pedagógica/pesquisa e suas implicações no debate epistemológico contemporâneo. Defendemos que tal problemática confere a educação ambiental crítica uma nova configuração teórica capaz de redimensionar o papel do educador ambiental face às mudanças conceituais que o emergente cenário interdisciplinar traz ao debate acadêmico e a educação ambiental atual.

Palavras-chave: educação ambiental crítica; Interdisciplinaridade; dialética marxista.

RESUMEN: Este ensayo se centra en la relación entre la interdisciplinariedad y la dialéctica marxista, a la luz de las cuestiones ambientales, y tendrá en cuenta los lazos que unen a la práctica como la enseñanza interdisciplinaria / investigación y sus implicaciones en el debate epistemológico contemporáneo. Argumentamos que estos temas de educación ambiental crítica da una nueva configuración teórica capaz de revalorizar el papel de los educadores ambientales frente a los cambios conceptuales que el escenario emergente trae a debate académico interdisciplinario y la educación ambiental actual.

Palabras clave: educación ambiental crítica, interdisciplinariedad, la dialéctica marxista.

\footnotetext{
${ }^{1}$ Texto apresentado e publicado com modificações no VI Encontro Nacional da ANNPAS/2012 - Universidade Federal do Pará - Belém.

2 Sociólogo. Doutorando em Educação Ambiental/FURG. Pesquisador do Laboratório de Investigações em Educação, Ambiente e Sociedade/LIEAS-UFRJ. E-mail: csc193@hotmail.com
} 


\begin{abstract}
This essay focuses on the relationship between interdisciplinarity and Marxist dialectic in the light of environmental issues, and will consider the bonds that unite as interdisciplinary teaching practice / research and its implications in contemporary epistemological debate. We argue that such issues critical environmental education gives a new theoretical configuration able to reassess the role of environmental educators face the conceptual changes that the emerging scenario brings to interdisciplinary academic debate and current environmental education.
\end{abstract}

Keywords: Critical Environmental Education; Interdisciplinary; Marxist dialectics.

\title{
INTRODUÇÃO
}

A interdisciplinaridade com seus problemas, avanços e desafios tem contribuído para problematizações importantes na área da pesquisa ambiental e da práxis pedagógica. $\mathrm{O}$ ambiente entendido em seus múltiplos aspectos sociais, políticos, econômicos e culturais é essencialmente interdisciplinar. A emergência e o entendimento da questão ambiental como problema interdisciplinar a partir de um conhecimento crítico, histórico e complexo são respostas não somente à crise da racionalidade da modernidade, mas, sobretudo pela produção social da ciência (FRIGOTTO, 2004) e seus interesses de classe. Refletir interdisciplinarmente é compreender na sua vertente de práxis ambiental (entendida como e enquanto política) sua historicidade, complexidade e totalidade que parte dos vários sentidos conferidos à mesma, sendo possível contribuir para o entendimento de seus vínculos ideológicos e científicos no campo ambiental.

Estaríamos nos limites da concretização das promessas da modernidade, a qual a ciência e a tecnologia nos libertariam das limitações da natureza e assim seríamos libertados. Todas as reflexões indicam neste cenário da discussão do ambientalismo como movimento social a crise civilizatória, crise dos referenciais epistemológicos, filosóficos e políticos que vêm sustentando a modernidade (QUINTAS, 2009). A partir destes pressupostos, este trabalho visa aproximar a interdisciplinaridade da educação ambiental crítica no que se refere às suas implicações à luz do método marxista. 


\section{BREVE HISTÓRICO DA INTERDISCIPLINARIDADE}

Historicamente a interdisciplinaridade surgiu no continente europeu, principalmente na França e Itália, em meio à década de 60, quando os movimentos estudantis tinham como sua principal reivindicação um novo estatuto de universidade. Tal questão apontava a alienação capitalista de algumas ciências, alienando a universidade dos problemas cotidianos e incitava o olhar dos seus alunos numa única e restrita visão de mundo. Frente a estes problemas, em 1961 propõe-se à UNESCO um projeto de pesquisa interdisciplinar para as ciências humanas, orientando-os rumo à convergência, em vista da unidade humana presenciada nos momentos de pesquisa. Paralelo a estes estudos, realiza-se um colóquio promovido pela Universidade de Louvain em 1967 entre teólogos, filósofos e sociólogos, que visava aparelhar o leigo católico para a missão da Igreja no mundo e a pensar sobre o estatuto epistemológico da teologia.

É “neste contexto das críticas ao atual modelo e padrão de conhecimento construído com a legitimação da ciência moderna, hegemônico no processo educativo institucionalizado, a temática da Interdisciplinaridade ganha notoriedade" (SILVA, 2009, p. 4). O termo interdisciplinaridade caracteriza-se pelo enfoque científico e pedagógico que se estabelece por um diálogo entre especialista de diversas áreas sobre uma determinada temática (ASSMANN, 1999).

\section{A INTERDISCIPLINARIDADE E A RELAÇÃO PRÁXIS DA/NA NATUREZA}

Ao adotarmos como referência a dialética marxista, compreendemos que ela não é apenas um método para se chegar à verdade, é uma concepção de homem, sociedade e da relação homem-mundo. Nesta conceituação entendemos que, no estudo do desenvolvimento de um fenômeno deve-se partir do seu conteúdo interno, das suas relações com outros fenômenos considerando o desenvolvimento interno dos mesmos como sendo o seu movimento próprio, necessário, interno, encontrando-se cada fenômeno em ligação com seu movimento, em ligação e interação com outros fenômenos que o cercam (MARX, 1988b). A dialética leva em conta a ação recíproca dos fenômenos buscando analisá-los e entendê-los numa totalidade:

A compreensão dialética da totalidade significa não só que as partes se encontram em relação de interna interação e conexão entre si e com o todo, mas também que o todo não pode ser petrificado na abstração situada por cima das partes, visto que o todo se cria a si mesmo nas interações das partes (KOSIK, 1978, p. 34). 
Assim, a discussão ambiental analisada em sua dimensão epistêmica e pedagógica, exige reflexões acerca da sua problemática. Aproximando estas categorias, e tentando adentrar em suas determinações, que encontramos uma pista que me parece fundamental para repensar os pressupostos teóricos sobre educação ambiental (EA), especialmente pelo seu caráter essencialmente histórico: a intervenção do ser humano no ambiente (MARX, 1993). Este ponto é crucial para pensar as categorias de análise, pois a intervenção humana no ambiente parece sintetizar elementos para a compreensão da problemática ambiental, mas também sintetiza, por seu caráter intencional, a problemática educacional (TOZONI-REIS, 2004).

Segundo Gorender, também em $O$ Capital a questão ambiental se apresenta de modo crítico no escopo marxista onde alude que:

\begin{abstract}
A humanização da natureza nem sempre tem sido um processo harmônico. Marx foi dos primeiros a apontarem o caráter predador da burguesia, com reiteradas referências, por exemplo, à destruição dos recursos naturais pela agricultura capitalista. Sob este aspecto, merece ser considerado precursor dos modernos movimentos de defesa da ecologia em benefício da vida humana. Do ponto de vista da Antropologia, o que sobreleva é a relação do homem com a natureza por meio do trabalho e a humanização sob o aspecto de autocriação do homem no processo de transformação da natureza pelo trabalho. As mudanças nas formas de trabalho constituem os indicadores básicos da mudança das relações de produção e das formas sociais em geral do intercurso humano. $\mathrm{O}$ trabalho é, portanto, o fundamento antropológico das relações econômicas e sociais em geral. Ou seja, em resumo, o que Marx propõe é a Antropologia do homo faber (GORENDER, 1996, p. 5-70).
\end{abstract}

A concepção dialética marxista não separa em nenhum momento teoria (conhecimento) da prática (ação), do qual a teoria não deve ser tomada como um dogma irrefutável, mas deve orientar, servir de modelo para a ação (GADOTTI, 1983; SCHMIED-KOWARZIK, 1983). Em consequiência, a prática será o critério de verdade da teoria, já que o conhecimento surge a partir da prática e a ela se volta dialeticamente. Exemplo clássico vem expresso por Marx em sua II Tese sobre Feuerbach, onde assevera que a questão de saber se cabe ao pensamento humano uma verdade objetiva não é uma questão teórica, mas prática. É na práxis que o homem deve demonstrar a verdade, isto é, a realidade, o caráter terreno de seu pensamento (MARX E ENGELS, 1977), sendo que sua concepção de práxis é válida na medida em que a teoria como guia de ação orienta a atividade humana, eminentemente revolucionária, e teórica, uma vez que se presta a uma relação consciente de sua atividade (VÁSQUEZ, 2008). $\mathrm{Na}$ esteira do pensamento marxiano, Gramsci concebe teoria e prática como filosofia da práxis, sendo um novo modo de pensar o mundo e realidade. Significado que desponta no contexto latino-americano marcado por contextos de desigualdades sociais como uma arma 
de luta, porque ela não simplesmente polemiza, mas serve à elaboração do pensamento crítico da realidade para transformá-la (GADOTTI, 1983).

\section{INTERDISCIPLINARIDADE E MATERIALISMO HISTÓRICO-DIALÉTICO}

Dentro deste panorama acima traçado, surge a necessidade de refletir qual o sentido da interdisciplinaridade e seu vínculo com o método dialético marxista para o contexto ambiental. Seria politicamente necessária; ou teoricamente não plausível? Estaria apta para enfrentar as práticas sociais vigentes? Tal problemática que incitamos, também deve abarcar uma dialética que não deve perder seu horizonte compreensivo; ser motor de prática, campo de reflexão sobre o social e o político, a qual tornaria sua ação impossibilitada. Aqui no país temos um aumento considerável na formação de cursos (principalmente de pós-graduação) que se dizem "interdisciplinares". É visível a referência e defesa em diversos trabalhos acadêmicos, pesquisas e encontros onde a interdisciplinaridade transita por diversos segmentos sociais e entre discussões de método, epistemologia e políticas educacionais, acabou se tornando um modismo sem exames mais atentos do que realmente significa a temática.

$\mathrm{Na}$ contramão deste cenário, aparecem proposições vinculadas à busca pela interdisciplinaridade na América Latina a diversas políticas relevantes em saúde, educação e ambiente, transitando sua ambivalência entre a (re) legitimação capitalista e a melhora da eficácia das práticas e aumento da democratização da atividade científica (FOLLARI, 2004). Concebemos que o vínculo entre Educação Ambiental, dialética marxista e interdisciplinaridade em sua fundamentação crítica, só poderá se manter enquanto materialidade que contribua para potencializar a transformação da práxis se assumir a criticidade das suas proposições. Uma crítica que se relaciona a radicalidade das suas lutas perante estruturas injustas visando à transformação da realidade e das subjetividades neste modo de produção capitalista. Negar o modo de produção social da ciência é afirmar o paradigma instaurado em nossas compreensões de Educação Ambiental que dissolveu a relação sociedade-natureza num só aspecto, o natural (LOUREIRO, 2006b), sem mensurar o caráter das mediações sociais. Significa continuar propondo uma Educação ambiental interdisciplinar linear, neutra, a-política, a-histórica e consubstancialmente desprovida de consciência crítica na visão do todo e das articulações! É defender que todo projeto em parceria é unicamente válido, visto que as diferenças epistemológicas na EA devem se 
deixadas ao largo, visto que a questão ambiental é muito maior que as diferenças políticas (entendida como mal a ser curado pela contribuição e parceria de outras áreas).

O contraponto que partimos para o debate ambiental é o aporte interdisciplinar originário do paradigma marxista dialético que surge como proposta crítica ao movimento existente. Assim, percebemos a necessidade da abordagem epistemológica da interdisciplinaridade de forma histórica e crítica, pois compreendemos uma perspectiva que fundamente que tal compreensão material e histórica não exclua a necessidade de avançarmos na produção do conhecimento. Entendemos que a necessidade do trabalho interdisciplinar se verifica na produção e na socialização do conhecimento no campo das ciências sociais e no campo educativo e o que desenvolve no seu bojo não decorre de um simples ato racional e abstrato. Decorre da forma do homem produzir-se enquanto ser social e enquanto sujeito do conhecimento, pois os homens na busca de satisfação de suas necessidades de natureza biológica, cultural, social e afetiva estabelecem diversas relações sociais. Para determinados grupos a produção do conhecimento e sua socialização não são alheias ao conjunto de práticas e relações que são produzidas na sociedade. Ao contrário, nelas encontra-se a sua efetividade na materialidade histórica! Daí, a necessidade de buscar compreender que a interdisciplinaridade na produção do conhecimento é fundada no caráter dialético da realidade social que é, una e diversa e na natureza intersubjetiva de sua apreensão (FRIGOTTO, 2004). Desse modo, a compreensão da categoria da totalidade concreta em contraposição à totalidade confusa e desordenada, vazia é necessária para assinalarmos a interdisciplinaridade como necessidade imperativa na construção do conhecimento social. Como adverte Kosik (1978), a totalidade não é tudo e nem a busca do princípio fundador de tudo. Analisar dentro da concepção de totalidade concreta significa buscar explicar, de um objeto de pesquisa delimitado, as múltiplas determinações e mediações históricas que o constituem.

Por consequiência, a necessidade que apontamos na produção do conhecimento não é prerrogativa apenas nas ciências sociais, embora nelas, mostra-se mais crucial, já que o alcance de uma maior objetividade (sempre relativa, porque histórica) somente será possível pelo debate crítico e intersubjetivo dos sujeitos que analisam uma determinada problemática (FRIGOTTO, 2004), pois o conhecimento vem atrelado por interesses, concepções, axiomas e condições de classe do pesquisador. Neste âmbito que percebemos que a interdisciplinaridade na produção do conhecimento é imperativa, mas é também uma questão que está lotada na materialidade das relações capitalistas de produção da existência. Em relação à importância do conhecimento vinculado à prática (MARX E ENGELS, 1977), asseguramos que a prática 
produtiva dos homens está antropologicamente equacionada por expressar a coletividade, pois a espécie humana é ímpar na medida em que se efetiva em sociedade (GADOTTI, 1983). Não se é humano fora de um tecido social constituinte como solo (base) de todas as relações sociais, uma vez que, o conhecimento não se estabelece a partir de nexos lógico-formais; ele se apresenta de maneira axiológica nos problemas de natureza ético-política (SEVERINO, 2004).

\section{INTERDISCIPLINARIDADE, MÉTODO DIALÉTICO E EDUCAÇÃO AMBIENTAL TRANSFORMADORA}

Na concepção de Dias (2003, p. 98), na perspectiva da Conferência Intergovernamental da Educação Ambiental de Tbilisi (1977), a Educação Ambiental passou a ter a seguinte definição: “dimensão dada ao conteúdo e à prática da educação, orientada para a resolução dos problemas concretos do meio ambiente através de enfoques interdisciplinares e de uma participação ativa e responsável de cada indivíduo e da coletividade." A Conferência Intergovernamental sobre educação Ambiental de Tbilisi propôs como um dos princípios básicos da Educação Ambiental: aplicar um enfoque interdisciplinar, aproveitando o conteúdo específico de cada disciplina, de modo que se adquira uma perspectiva global e equilibrada. Segundo Dias (2003, p. 117), "pela própria natureza do ambiente, dadas as suas múltiplas interações de fundo ecológico, político, social, econômico, ético, cultural, científico e tecnológico, não se poderia tratar o assunto em uma única disciplina." Uma importante contribuição neste aspecto está contemplada nos Parâmetros Curriculares Nacionais através da transversalidade dos temas, cujo meio ambiente é um deles.

Para tentar colocar em prática as recomendações a da Conferência de Tbilisi o Brasil aprovou e sancionou A Lei 9795/99 Política Nacional de Educação Ambiental estabelecendo a educação ambiental como um componente essencial e permanente da educação nacional, devendo estar presente, de forma articulada, em todos os níveis e modalidades do processo educativo, em caráter formal e não-formal que deverá ser desenvolvida como uma prática educativa integrada, contínua envolvendo todos os professores. $\mathrm{Na}$ verdade, a abordagem interdisciplinar defende a superação da fragmentação do saber. A abordagem interdisciplinar das questões ambientais implica em utilizar a contribuição das várias disciplinas (conteúdo e método) para se construir a compreensão e explicação do problema tratado e desse modo, superar a compartimentação. Implica, também, em envolver as populações e valorizar seus conhecimentos. 
O enfoque interdisciplinar preconiza a ação das diversas disciplinas em torno de temas específicos. Assim, torna-se imperativa a cooperação/ interação entre todas as disciplinas. Ultimamente, tem sido, muito grande as contribuições por parte das artes, dado o seu grande potencial de trabalhar com sensibilização, elemento essencial para comunicar-se efetivamente. Antes, a EA ficava restrita à área de Ciências ou Biologia, o que foi um erro. Precisamos praticar a EA de modo que ela possa oferecer uma perspectiva global da realidade e não uma perspectiva científica e biológica apenas. São importantes os aspectos sociais, históricos, geográficos, matemáticos, de línguas, da expressão corporal, da filosofia, etc (DIAS, 2003, p. 117).

Enrique Leff (2001), ao explicitar o debate entre interdisciplinaridade e educação ambiental, defende um novo arranjo entre ciência e saber, entre tradição e modernidade que valorize conhecimentos indígenas e saberes populares não relacionados a mercantilização, mas, a culturas diferentes. Segundo Leff (2001), a crise ambiental é uma crise de conhecimento do mundo que não repensa o ser do mundo complexo. A solução desta crise não se dá na racionalidade teórica e instrumental, mas, na reconstrução de um novo saber na medida em que parte do conhecimento das raízes dessa crise. Ele critica a intenção de enfrentar a questão ambiental através da ecologia, pois, a necessidade é de relacionar as várias ciências através da interdisciplinaridade. O saber e método interdisciplinares representam não só a fusão e integração dos conhecimentos provenientes de diferentes ciências, mas a reformulação de seus paradigmas de conhecimento a partir dos problemas sociais, históricos e, portanto, ambientais que se apresentam (SILVA, 2009). A interdisciplinaridade precisa ser repensada em sua historicidade.

\begin{abstract}
A interdisciplinaridade surge como uma necessidade prática de articulação de conhecimentos, mas constitui um dos efeitos ideológicos mais importantes sobre o atual desenvolvimento das ciências, justamente por apresentar-se como o fundamento de uma articulação teórica. Fundada num princípio positivista do conhecimento, as práticas interdisciplinares desconhecem a existência dos objetos teóricos das ciências; a produção conceitual dissolve-se na formalização das interações e relações entre objetos empíricos. Desta forma, os fenômenos não são captados a partir do objeto teórico de uma disciplina científica, mas surgem da integração das partes constitutivas de um todo visível (LEFF, 2001, p. 36).
\end{abstract}

Tais propostas encontraram no paradigma da complexidade para o conhecimento, que Edgar Morin (2000), um novo método para o saber. Não se trata de buscar o conhecimento geral nem uma teoria unitária, mas sim de encontrar um método que detecte as ligações e articulações. Para Morin, a complexidade ambiental se refere no sentido de que a vida se constitui por dimensões conexas, definidas mutuamente pelas relações estabelecidas, envolvendo ordem e desordem, erro e acerto, risco e incerteza numa reorganização permanente (MORIN, 1999). Portanto, complexidade incide transformação contínua para 
superar paradigmas simplificadores que operam a disjunção homem-natureza ou que reduzem o ser humano à natureza de modo indistinto.

Outrora, a atual complexidade ambiental, tem se caracterizado como a expressão do reconhecimento da crise civilizatória e pela projeção de um pensamento e ações complexas orientadas no sentido de reconstruir o mundo sob novas bases na relação sociedade-natureza (LEFF, 2001). Essa concepção vem de modo reforçar o fundamento e a sustentação na dialética histórica para pensarmos a complexidade e o ambiente. Por sua vez, a dialética e sua efetividade crítica é o exercício complexo e totalizador que permite apreender a síntese das múltiplas determinações. Isso não significa um estudo da totalidade da realidade (vista que ela seria inesgotável), mas compreender de modo racional tal realidade como um todo estruturado no qual o entendimento da realidade como um todo estruturado não se pode compreender um aspecto sem relação com o conjunto. Possibilita compreender que o singular tem sentido em suas relações (totalizações) e que o todo é mais que a soma de singularidades, ou seja, busca integrar teoria e práxis, subjetividade, individualidade, matéria e idéia no processo de historicidade (LOWY, 2002). Logo, a concepção dialética implica que qualquer objeto que possamos perceber faz parte de um todo, por isso é preciso a busca de soluções das questões depende de uma visão de conjunto, sempre provisória e que não tem a pretensão de esgotamento do real (KONDER, 1997), mas torna-se fundamento para que possamos analisar a dimensão de cada elemento dentro de uma estrutura (LOUREIRO, 2006a). Defendemos e queremos apontar para a busca de uma originalidade entre dialética, interdisciplinaridade e ambiente que dê vazão aos engajamentos histórico-políticos da realidade latino-americana, bem como da construção de um pensamento vivo, crítico, humanístico e libertador na maneira de conceber a sociedade.

Educação Ambiental é dimensão da educação, é atividade intencional da prática social, que imprime ao desenvolvimento individual um caráter social em sua relação com a natureza e com os outros seres humanos, com o objetivo de potencializar essa atividade humana, tornando-a mais plena de prática social e de ética ambiental. Essa atividade exige sistematização através de metodologia que organize os processos de transmissão/apropriação crítica de conhecimentos, atitudes e valores políticos, sociais e históricos. Assim, se a educação é mediadora na atividade humana, articulando teoria e prática, a educação ambiental é mediadora da apropriação, pelos sujeitos, das qualidades e capacidades necessárias à ação transformadora responsável diante do ambiente em que vivem. Podemos dizer que a gênese do processo educativo ambiental é o movimento de fazer-se plenamente humano pela apropriação/transmissão crítica e transformadora da totalidade histórica e concreta da vida dos homens no ambiente (TOZONI-REIS, 2004, p. 147). 


\section{CONSIDERAÇÕES FINAIS}

Apontamos que no campo epistemológico crítico há a necessidade de superarmos as formulações advindas da filosofia do sujeito como afirmam Jantsch e Bianchetti (2004). Para isso, é relevante contextualizar historicamente o advento da fragmentação ocorrida e imposta pela divisão do trabalho. Ao mesmo tempo é preciso entender que a interdisciplinaridade ocorre na relação entre disciplinas, uma vez que, para uma formulação crítica de interdisciplinaridade que caberia à formulações de educação ambiental é preciso transformar a disciplina. De qualquer forma não é possível uma interdisciplinaridade sem a disciplina. Ao buscar a interdisciplinaridade vinculada à educação ambiental crítica é preciso ter visão crítica da própria ciência. Nesse processo de busca pela mudança paradigmática da interdisciplinaridade e educação ambiental crítica é necessária a construção de mediações (SILVA, 2009), pois tanto o educador, quanto o educando seriam reconhecidos enquanto pesquisadores. Esse reconhecimento vem com a idéia de um cientista e de uma ciência em constante construção e diversidade.

Assim, ser interdisciplinar é reconhecer-se dentro de um processo em construção, sendo pautados pela problematização da disciplina e dessa com suas interconexões sociais, culturais e ambientais. Acima de tudo nessa construção interdisciplinar é preciso considerar a ação radical de coexistência entre intervenção humana e o ambiente. Para um enfoque interdisciplinar crítico na Educação Ambiental, urge analisarmos como as relações sociais estão situadas num horizonte social e político mais amplo do que somente repetirmos fórmulas a-históricas que se tornam vazias, repetidas e carentes de um exame mais dialético na maneira de compreendermos o conhecimento da realidade como único e universal. Por fim, cabe aos processos de busca da interdisciplinaridade e educação ambiental crítica refletir sobre a dinâmica política necessária para a relação homem-natureza (TOZONI-REIS, 2004).

\section{REFERÊNCIAS BIBLIOGRÁFICAS}

ASSMANN, Hugo. Reencantar a educação. Petrópolis: Vozes, 1999.

BIANCHETTI, Lucídio; JANTSH, Ari (Orgs). Interdisciplinaridade. Para além da filosofia do sujeito. In: BIANCHETTI, Lucídio; JANTSH, Ari (Orgs.). Interdisciplinaridade. Para além da filosofia do sujeito. Petrópolis: Vozes, 2004. p. 11-24. 
DIAS, Genebaldo Freire. Educação ambiental: princípios e práticas. 8.ed. São Paulo: Gaia, 2003.

ETGES, N. J. Ciência, interdisciplinaridade e educação. In: JANTSCH, A. P; BIANCHETTI, L. (Orgs.) Interdisciplinaridade - para além da filosofia do sujeito. Petrópolis: Vozes, 2004.

FAZENDA, Ivani C. A. Integração e interdisciplinaridade no ensino brasileiro: efetividade ou ideologia. São Paulo, Loyola, 1979.

FAZENDA, I. Interdisciplinaridade: um projeto em parceria. São Paulo: Loyola, 1991.

FRIGOTTO, Gaudêncio. A interdisciplinaridade como necessidade e como problema nas ciências sociais. In: JANTSHI; Ari; BIANCHETTI, Lucídio. (Orgs.). Interdisciplinaridade. Para além da filosofia do sujeito. Petrópolis: Vozes, 2004.

GADOTTI, Moacir. Interdisciplinaridade: atitude e método. Disponível em: http://tingunispsollmatematico.blogspot.com/2010/08/interdisciplinaridade-atitude-e-metodo.html Acesso em: 01/03/2012.

. Concepção dialética da educação. São Paulo: Cortez, 1983.

GORENDER, Jacob. Apresentação. In: Os economistas. O Capital. São Paulo: Nova Cultural, 1996. .

GRAMSCI, Antonio. A Concepção dialética da história. Rio de Janeiro: Civilização Brasileira, 1978.

JANTSCH, Ari Paulo; BIANCHETTI, Lucídio. Imanência, Historia e Interdisciplinaridade. In: JANTSCH, Ari Paulo; BIANCHETTI, Lucídio (Orgs.). Interdisciplinaridade: para além da filosofia do sujeito. Petrópolis: Vozes, 2004.

JAPIASSU, Hilton. Interdisciplinaridade e patologia do saber. Rio de Janeiro: Imago, 1976.

KONDER, Leandro. O que é Dialética. São Paulo: Brasiliense, 1997.

KOSIK, Karel. Dialética do concreto. Rio de Janeiro: Paz e Terra, 1978.

LEFF, Enrique. Epistemologia ambiental. São Paulo: Cortez, 2001.

. (Coord.). A complexidade ambiental. São Paulo: Cortez, 2003.

LOUREIRO, Carlos Frederico Bernardo. Trajetória e fundamentos da Educação Ambiental. São Paulo: Cortez, 2006a.

Educação Ambiental Transformadora. In: LAYRARGUES, Philippe Pomier (coord). Identidades da educação ambiental brasileira / Ministério do Meio Ambiente. Diretoria de Educação Ambiental; Ministério do Meio Ambiente, 2004.

Problematizando conceitos: contribuição à práxis da Educação Ambiental. In: LOUREIRO, C. F. B; LEROY, J. P. (Orgs.). Pensamento complexo, dialética e Educação Ambiental. São Paulo: Cortez, 2006e.

LOUREIRO, C. F. B (Org.). A Questão ambiental no pensamento crítico. Rio de Janeiro: Quartet, 2007b.

LOWY, M. A teoria da revolução no jovem Marx. Petrópolis: Vozes, 2002.

MARX, Karl; ENGELS, Friedrich. A Ideologia alemã. São Paulo: Grijalbo, 1977.

MARX, K. Manuscritos Econômicos-filosóficos. Edições 70, 1993. 
1985, v. I, t. 1.

MARX, Karl. O Capital: crítica da economia política. São Paulo: Nova Cultural,

MARX, K. Posfácio à 2 edição 1983. In: MARX, K. O Capital. São Paulo: Abril Cultural, 1983.

. Teses contra Feuerbach. In: Os Pensadores. São Paulo: Abril Cultural, 1988.

. Para a crítica da economia política. Introdução. In: Os Pensadores. São Paulo: Abril Cultural, 1988b.

MORAN, Edgar. O Paradigma perdido: a natureza humana. Lisboa: Europa-América, 1999.

MORIN, Edgar. Educação e complexidade os sete saberes e outros ensaios. São Paulo:

Cortez, 2005.

A inteligência da complexidade. São Paulo: Fundação Petrópolis, 2000.

O problema epistemológico da complexidade. Lisboa: Europa-América, s/d.

O Método I: a natureza da natureza. 2 ed. Porto Alegre: Sulina, 2003.

QUINTAS, José da Silva. Educação no processo de gestão ambiental pública: a construção do ato pedagógico. In: LOUREIRO, C. F. B; LAYRARGUES, P (Orgs.). Repensar a educação ambiental: um olhar crítico. São Paulo: Cortez, 2009.

SEVERINO, Antônio. O uno e o múltiplo: o sentido antropológico do interdisciplinar. In: JANTSH; Ari; BIANCHETTI, Lucídio. (Orgs.). Interdisciplinaridade. Para além da filosofia do sujeito. Petrópolis: Vozes, 2004.

SILVA, Luciana Ferreira. Reflexões sobre interdisciplinaridade e educação ambiental crítica. Pesquisa em debate, edição 11, v. 6, n. 2, jul-dez. 2009.

TOZONI-REIS, M. Educação Ambiental: natureza, razão e história. Campinas, São Paulo: Autores Associados, 2004.

VÁSQUEZ, Adolfo Sanchez. Filosofia da Práxis. São Paulo: Expressão Popular, 2008. 